\title{
Uma crítica sobre os processos midiáticos de exclusão
}

\section{A critique of media processes of exclusion}

Andrea Limberto ${ }^{1}$

1 Doutora em Ciências da Comunicação pela Escola de Comunicações e Artes da Universidade de São Paulo (ECA-USP). 
Resumo

Resenha do livro SOARES, R. L. Sutileza e grosseria da exclusão nas mídias. São Paulo: Alameda, 2020.

Palavras-chave

Cultura audiovisual, crítica de mídia, estigmas sociais, discursos, narrativas.

\section{Abstract}

Review of the book SOARES, R. L. Sutileza e grosseria da exclusão nas mídias. São Paulo: Alameda, 2020.

\section{Keywords}

Audiovisual culture, media criticism, social stigmas, discourses, narratives. 


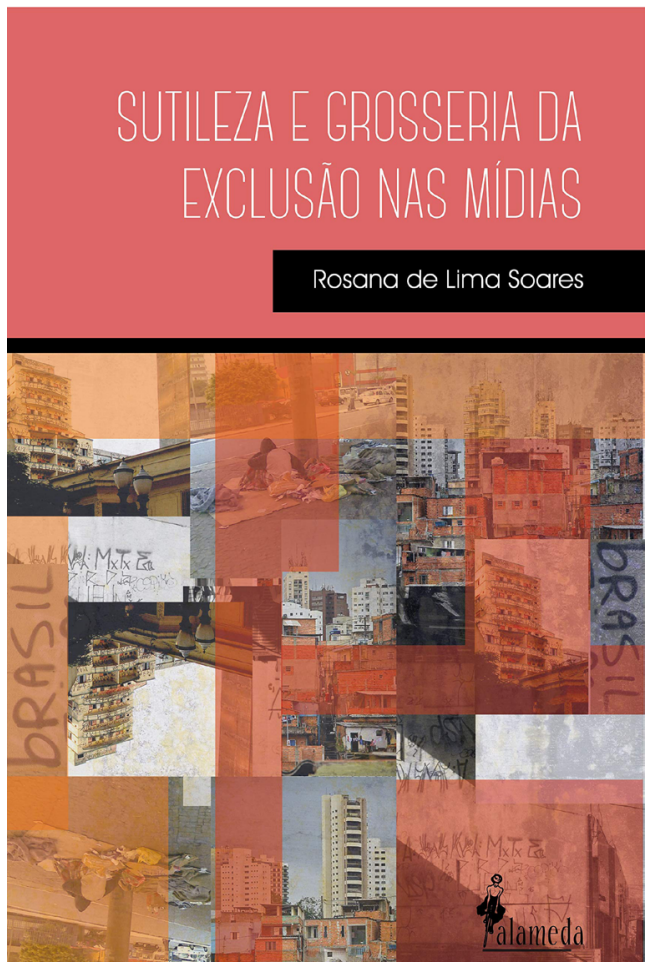

A obra Sutileza e grosseria da exclusão nas mídias, de Rosana de Lima Soares (2020), é lançada num momento em que precisamos de apontamentos para seguir fazendo pesquisas acadêmicas que se apoiem numa perspectiva crítica e que possam nos ajudar a pensar como agir enquanto sujeitos sociais. Uma visão assim não pode ser obtida no calor do momento; exige maturidade acadêmica e investimento de décadas em pesquisa. Isto porque a ação do tempo permite observar as viradas das linguagens das mídias, seus deslocamentos e o que significa essa atuação e em nome do que ela se levanta num ambiente de camadas tensas e mediadas pela visibilidade. O livro, publicado pela Alameda e originalmente apresentado em forma de tese de livre-docência na área de Jornalismo e Linguagem, defendida em 2015 na Escola de Comunicações e Artes da Universidade de São Paulo (ECA-USP), recupera mais de uma década de pesquisa (2003-2015), em que a autora se concentrou nos estudos de mídia em um sentido amplo, visto que são discutidos tanto a especificidade das materialidades abordadas quanto os desafios a própria limitação genérica para entendermos o que é mídia. Enquanto temática, a autora aponta para as dinâmicas de estigmatização, estereotipação e de exclusão abordando-as 
e acercando o problema conceitualmente, pois tais dinâmicas não estão dadas, ao mesmo tempo que as opera no sentido das análises.

Ainda que o tempo de uma trajetória de investigação não dê conta de todo o movimento de formação da nossa dinâmica midiática, em cada um dos objetos reside, resiste e se concentra a história pregressa, oferecida para que seus nós - a questão das exclusões, dos estigmas, das violências e das possibilidades de construção de algo nos lugares midiáticos marcados por visibilidade, saber e poder - sejam desamarrados. Isso é relevante, pois nos ajuda a ver caminhos que vão além da ideia de representação midiática e de um engessamento estático, como muitas vezes são pensadas as dinâmicas de identidade, e que façam jus às presenças plurais dos sujeitos e às dinâmicas entendidas na linha dos estudos de linguagem, em especial sobre o que é do domínio da narrativa, dos discursos e do pensamento sobre o real.

O livro encontra-se dividido em três partes que, de maneira inteligente, não se fixam em um ponto central, mas nos convidam para um percurso por vezes em ciranda, articulando produções midiáticas, mas muitas vezes em um nó inspirado no nó borromeano de Lacan - que não se engole. Assim, estudamos vazões imaginárias nas articulações narrativas nas mídias (Parte I), marcas estruturantes nas articulações discursivas nas mídias (Parte II) e um escape bem real, pensando os novos realismos nas mídias (Parte III). Se os estigmas são entendidos como processos estruturais, sua presença e o combate a eles devem estar em todas as partes, em todos esses níveis. Ademais, a visada deve ter flexibilidade para ser sempre crítica na recuperação teórica, na metodologia e no recorte do objeto.

As narrativas aparecem como um caminho mais natural e palatável de entrada, uma vez que ambientam visões, sonhos, projeções e imaginários. Mas essa porta aberta de forma alguma é um escape e um descolamento em relação às factualidades e a um contato com realidades que estão nelas pulsionando as viagens narrativas. Em sua primeira parte, o livro subdivide a vivência das narrativas midiáticas considerando estigmas em jornais e revistas: (1) primeiras leituras; (2) estigmas em telejornais diários: primeiras chamadas; (3) estigmas em filmes: primeiras imagens. 
Como metáfora sígnica de uma doença, como se pode pensar com Sontag (1989), a questão da Aids, que mereceu atenção na base das pesquisas da autora (SOARES, 2001), continua mostrando desdobramentos tanto como tema sensível quanto como maneira de olhar processos de marcação na linguagem. Vemos seu desdobramento e ampliação para outros temas listados nas preocupações contemporâneas sobre os processos de alteridade na mídia, que dizem respeito, reciprocamente, aos imaginários dos próprios temas e, com a mesma intensidade, devolvem sobre como devemos criticar os processos midiáticos em seus propósitos de repetições e diferenças. São destacadas como temáticas sensíveis hoje: questões de gênero, questões étnicas, questões rurais ou urbanas, ambientalismo, povos indígenas, tráfico de drogas e, sobretudo nas mídias audiovisuais, temas relacionados à violência, imigração, pobreza e exclusão social, retratando em suas imagens sujeitos em situação de risco ou vulnerabilidade.

A abordagem da obra é sofisticada não só nas temáticas, mas também no acionamento dos conceitos e na variedade dos suportes. Dessa forma, a pluralidade em todos esses sentidos corrobora para uma metodologia que favorece a formulação da própria questão hipotética de base sobre os estigmas, acionando interdisciplinarmente áreas que, podemos dizer pelo contrário, foram incididas pelas dinâmicas de exclusão social: a Antropologia, a Sociologia, a Filosofia, a Psicanálise, as ciências da linguagem, os estudos culturais, as teorias do cinema e do audiovisual e a Comunicação.

Conceitualmente, o desafio se coloca em refazer as relações e ir além do que está solidificado nas identidades, na representação, nas visibilidades e nos reconhecimentos, não para retirar a estrutura de apresentações afirmativas, mas para exercitar uma crítica sobre a destinação dos lugares sobre os quais as afirmações estão dadas. Nesse percurso, é importante investigar as fronteiras entre as produções classificadas na referencialidade e aquelas classificadas na ficcionalidade.

A autora apresenta a ideia de narrativas de caráter realista, que podemos entender como traços factuais que marcam as produções e que, inicialmente, fazem o desenho da mancha gráfica para, depois, na última parte do livro, 
ganharem formas novas e atuais dentro da chave dos realismos. O objetivo maior é observar e questionar as produções midiáticas como lugares de reforço e/ou transposição de processos de exclusão e inclusão e sair identificando estigmas, mas escapar diferenciando preconceitos e estereótipos.

Na segunda parte, o livro passa da observação de recorrências narrativas para o fato de que elas indicam um conhecimento comum em termos de formatos e de gêneros, ora marcando-os, ora desafiando-os. A reiteração de visualidades reafirma e, ao mesmo tempo, contamina formatos apontando para deslocamentos possíveis e novas visibilidades em novas formas discursivas. O capítulo II trata, assim, das articulações discursivas nas mídias, considerando: (1) a referencialidade e a ficcionalidade em narrativas audiovisuais; (2) as convergências e hibridismos em gêneros impuros; (3) os estigmas sociais e subjetividades: (in)visibilidades encenadas. A autora faz, ainda, uma incursão detalhada por produções audiovisuais contemporâneas e discute os elementos que tentam explicar os giros entre formatos e formatos discursivos como marcas de interatividade, colaboração, não-linearidade, fragmentação e hipertextualidade.

A presença dessas estratégias discursivas, mais do que indicarem pontualmente renovações formais, desafiam as construções de verdade e realidade dentro das narrativas, retomam a assunção de objetos e sujeitos a partir do questionamento do que é a sua representação fiel e objetiva, historicizam e contextualizam discursivamente sua presença e fazem da discussão proposta pela autora, ao longo de toda a obra, uma visada sobre os hibridismos como sintoma do momento atual. "A fala que se apresenta é um balbucio, uma busca do discurso em encontrar seu giro, seu lugar, mas é no vazio deste eixo ordenador que as histórias são contadas" (SOARES, 2020, p. 154).

Talvez o passo mais instigante do trabalho, por representar uma virada crítica, seja a indicação de uma possibilidade de entender os processos de subjetivação de maneira não essencializada, mas justamente em um processo que toma os sujeitos à revelia e reorganiza um pensar sobre si, colocando-o em outro lugar. Será esse lugar o do estigma social ou haverá uma margem, 
haverá uma estranheza na ordem do discurso? Assim, discursos polifônicos e heterogêneos são acionados como levante de vozes de sujeitos plurais, em processos certamente tensos de mediação, mas que buscam gerar transformações. Quando os sentidos são desestabilizados e as ambiguidades são assumidas na realidade, em sua estrutura de ficção e fixação, propõem-se questionamentos com relação às políticas da representação e aos regimes de visibilidade, que incluem, especialmente, sujeitos periféricos.

Dessa reflexão, extrai-se uma diferenciação de termos-conceito, como estigmas, preconceitos e estereótipos, muitas vezes usados em outros trabalhos de forma descuidada e intercambiável.

Nesse sentido, retomamos a diferenciação entre preconceitos, estereótipos e estigmas: enquanto os primeiros circulam em torno da afirmação ou contestação dos discursos manifestos, o último diz respeito a embates entre formações discursivas em posições hegemônicas ou contra-hegemônicas. Os preconceitos e estereótipos visam acomodação e restabelecimento da ordem social, fazendo com que mesmo aqueles considerados outsiders sejam mantidos em seus lugares, sem perturbá-la; os estigmas, por sua vez, são desestabilizadores, pois podem propor reordenamentos e a irrupção de uma nova ordem, que só encontrará lugar se houver ruptura nos discursos correntes. (SOARES, 2020, p. 156)

Considerando o avanço dos trabalhos de análise, especialmente aqueles concentrados sobre as produções audiovisuais, aparece um desencaixe entre a imagem vista na cena narrativa imaginária, bem como seus contornos tracejados nas articulações discursivas, e a realidade da sua especificidade performática, isto é, narrativas que não apenas informam, mas também, e ao mesmo tempo, performam. A autora expõe, então, a urgência em estabelecer uma perspectiva crítica nas análises de discursos midiáticos. No capítulo III, Soares (2020) trata dos ditos novos realismos nas mídias, considerando-os sob as perspectivas: (1) das políticas da representação e regimes de visibilidade em práticas culturais; (2) da cultura audiovisual: visibilidades periféricas e reconhecimento social; (3) da crítica de mídia e estigmas sociais: entre reconhecimento e resistência. 
A questão perseguida ao longo do trabalho retorna constantemente, reformulada no sentido de acrescentar um ponto de partida do percurso já realizado. Se o estigma é aquilo que se encontra deslocado e, por isso, nos desafia, uma última questão se coloca: como diferenciar, por meio da análise, uma contestação acomodada e uma postura crítica transformadora? Seguindo sua vocação, as artes nos desarmam dissolvendo posições enraizadas, como se, por meio delas, fosse possível pontuar o real que insiste em estar ainda alheio, em pertencer a um imaginário sempre redutor e precário, mas o único espaço possível de trocas simbólicas (SOARES, 2020).

Apresenta-se, então, um percurso em três tempos para a análise de produções audiovisuais, realizando uma incursão crítica que inclui pensar o próprio formato documental, questionar os modos de captura do outro e apontar caminhos fora da cena do visível. Há um pretenso paradoxo que é conceitualmente interessante para o deslindamento - ou uma nova volta - nos nós. O momento máximo de ausência no campo do visível é também aquele de maior insistência, se os processos de mediação garantem que essa tensão esteja presentificada como formas da (in)visibilidade documentada. Considerando a expressão novos realismos (Jaguaribe, 2007), Soares (2020) investiga modos de percepção da realidade incluindo as vivências de reality shows no reverso das suas presenças visibilizadas.

A relevância da obra para a atualidade se dá ao olharmos para esse grande e diverso levantamento que cumpre seu fôlego tanto quantitativo quanto qualitativo e ao sermos incentivados a continuar girando a roda dos nós. Ainda, é importante que esse movimento seja no sentido de buscar caminhos e que estes sejam críticos desde o ponto em que nos inclui como sujeitos da pesquisa e que nos faça movimentar apoios coletivos.

Essa necessidade pode ser tomada como orientação por quem lê, porque o trabalho mostra - enquanto se realiza - o quanto estamos formados nos processos midiáticos, o quão plurais eles são e o quão emergencial é o apelo por produções mais inclusivas, mais polifônicas e que caiam rapidamente num abismo real, mas ressurjam dos contatos com as mobilizações sociais. 
A autora enfatiza as temáticas relacionadas à exclusão, à pobreza, à violência, aos conflitos e aos modos de superá-los, bem como pontua que a atribuição de juízos de valores relacionados aos estigmas os hierarquiza em termos de aceitação ou rejeição, variando de acordo com contextos históricos e culturais. Ademais, Soares (2020) renova a questão central do seu investimento, que fica para nós: "[...] como propor modos de representação do 'outro' da forma mais ativa (e altiva) possível?" (SOARES, 2020, p. 262). Preservemos o respeito e o direito às diferenças nas hierarquias dos discursos, para que a nossa atividade narrativa rode sem fim e a nossa altivez, vinda do nada, seja tudo.

\section{Referências}

JAGARIBE, B. O choque do real: estética, mídia e cultura. Rio de Janeiro: Rocco, 2007.

SOARES, R. L. Imagens veladas: aids, imprensa e linguagem. São Paulo: Annablume, 2001.

SOARES, R. L. Sutileza e grosseria da exclusão nas mídias. São Paulo: Alameda, 2020.

SONTAG, S. Aids e suas metáforas. São Paulo: Companhia das Letras, 1989.

submetido em: 12 dez. 2021 | aprovado em: 13 dez. 2021 